\title{
Accelerated thermal ageing of epoxy resin and 3-D carbon fiber/epoxy braided composites
}

\author{
Man Zhang, Baozhong Sun, Bohong Gu* \\ College of Textiles, Donghua University, Shanghai, China, 201620 \\ (*: Tel: 86-21-67792661 Fax: 86-21-67792627Ｅ-mail: gubh@dhu.edu.cn)
}

\begin{abstract}
This paper reports the accelerated thermal ageing behaviors of pure epoxy resin and 3-D carbon fiber/epoxy braided composites. Specimens have been aged in air at $90{ }^{\circ} \mathrm{C}$, $110{ }^{\circ} \mathrm{C}, 120{ }^{\circ} \mathrm{C}, 130{ }^{\circ} \mathrm{C}$ and $180{ }^{\circ} \mathrm{C}$. Microscopy observations and attenuated total reflectance Fourier transform infrared spectrometry analyses revealed that the epoxy resin oxidative degradation only occurred within the surface regions. The surface oxidized layer protects inner resin from further oxidation. Both the resin degradation and resin stiffening caused by post-curing effects will influence the compression behaviors. For the braided composite, the matrix ageing is the main ageing mode at temperatures lower than glass transition temperatures ( $\mathrm{Tg}$ ) of the pure epoxy resin, while the fiber/matrix interface debonding could be observed at the temperatures higher than $\mathrm{Tg}$, such as the temperature of $180{ }^{\circ} \mathrm{C}$. The combination of matrix degradation and fiber/resin interface cracking leads to the continuous reduction of compressive behaviors.
\end{abstract}

Keywords: A. Fabrics/textiles; B. Environmental degradation; D. Thermal analysis; E. Braiding. 


\section{Introduction}

In the design of the new generation of aircraft structures, three-dimensional (3-D) braided composite is currently widely used due to its excellent through-thickness properties, high damage tolerance and fatigue resistance [1]. The aerospace applications require a long service life of materials, in particularly in harsh environments (temperature, oxidizing environment, etc.). Hence, the effects of thermal ageing on the mechanical properties of the 3-D braided composites are considered vitally important for aircraft design.

Currently, the studies have mainly concentrated on characterizing degradation and damage initiation. Tsotsis [2-5] found that the weight loss during thermo-gravimetric test could not be used as criteria for material acceptance. The properties' changes, such as mechanical properties [6-12], physical properties [13], thermal conductivity [14] and the development of microcracks [15-17] caused by thermal treatment have been extensively studied and documented. Compared with isothermal ageing, thermal cycling can accelerate the damage processes and especially the matrix crack propagation from the surfaces to the core of the laminate [18].

It was found that there are two step changes in the mechanical properties under thermal ageing [19]. In the first consolidation stage, owing to the post-curing reaction, there are improvements in the mechanical properties. In the second degradation stage, the mechanical properties decreased significantly. For pure epoxy, the thermo-oxidative ageing can be characterized by three phases [20]. The first phase is dominated by the polymer viscoelastic behavior and by stress relaxation at high temperature. The second phase is characterized by thermo-oxidative matrix shrinkage and change of the instantaneous matrix elastic modulus with time. The third phase is attributed to the development of microcracks.

In the thermal degradation of composite materials, the oxygen pressure is an accelerating factor [21-23]. The thermal ageing process was controlled by the oxygen diffusion and the thickness of oxidized layer [24-26]. Instrumented ultra-micro indentation was used to characterize the mechanical property of an oxidized epoxy 
polymer. And the experimental measures agreed well with the predicted values of an oxidation model $[27,28]$.

The degradation mechanism also strongly depends on the specimen geometry and anisotropy $[29,30]$. Nam and Seferis [31] found that the property degradation was significantly dependent on the fiber orientation pertaining to the composite anisotropy. The work of Mlyniec et al [32], similarly, concluded that the alignment of the reinforcing fibers would affect long term damping performance of the carbon/epoxy composites. Stability of the modal damping of unidirectional carbon/epoxy laminates is affected mainly by the properties of the fiber-matrix interface, while the quasi-isotropic laminates depends mainly on long-term properties of the matrix. Surfaces with different microstructural characteristics, on the other hand, could be expected to exhibit different oxidation behavior [11,33].

The degradation is often investigated under accelerated conditions at elevated temperatures. As described above, the mechanical properties of composite are more dependent on the matrix and thus more sensitive to thermal ageing. In this paper, both pure epoxy resin and three-dimensional carbon/epoxy braided composites were exposed to an isothermal high-temperature environment. Their micro-morphologies and compressive behaviors after thermal ageing were presented. From the experimental results, we also investigated the influence of the temperature on the thermal ageing mechanisms.

\section{Experimental}

\subsection{Materials and specimens}

The materials used in this study were T700S-12K carbon fiber supplied by Toray Inc. (Japan) and JA-02 epoxy resin supplied by Changshu Jiafa Chemical Inc. (China). The 3-D braided preform (shown in Fig.1) with square cross section of $11 \times 11$ braiding yarn arrays, was manufactured with a four-step $1 \times 1$ braiding technique. Epoxy resin was injected into the braided preform with vacuum assisted resin transfer molding (VARTM) technique. Curing process followed a stepwise program of $90{ }^{\circ} \mathrm{C}$ 
for $2 \mathrm{hrs}, 110{ }^{\circ} \mathrm{C}$ for $1 \mathrm{hr}$, and $130{ }^{\circ} \mathrm{C}$ for $4 \mathrm{hrs}$. For comparison, an epoxy cube was also prepared at the same conditions. Ageing is not considered during curing process. The surface braiding angle for the braided composite is $20^{\circ}$. The fiber volume fraction is $38 \%$. The braided composite was cut into about $12.2 \mathrm{~mm}$ along longitudinal direction which equals to the size of the braided cross section, i.e., the size of the braided composite cube is $12.2 \mathrm{~mm} \times 12.2 \mathrm{~mm} \times 12.2 \mathrm{~mm}$. The epoxy cube has the same size with the braided composite coupon.

\subsection{Thermal ageing}

The isothermal ageing was accomplished in an air-circulating oven which provided a continuous replenishment of oxygen in the ambient air. The glass transition temperatures $\left(\mathrm{T}_{\mathrm{g}}\right)$ of pure epoxy resin and the 3-D braided composite, measured by the dynamic mechanical analyses (DMA), were equal to $110^{\circ} \mathrm{C}$ and $130{ }^{\circ} \mathrm{C}$, respectively. Based on the values of $\mathrm{T}_{\mathrm{g}}$, five temperature points $\left(90^{\circ} \mathrm{C}, 110^{\circ} \mathrm{C}, 120^{\circ} \mathrm{C}\right.$, $130^{\circ} \mathrm{C}$, and $180^{\circ} \mathrm{C}$ ) were selected to explore the temperature effects on thermal ageing. Before ageing, all specimens were dried in oven at $80{ }^{\circ} \mathrm{C}$ for 1 hour. Moisture effects were not considered in this study. With a short drying time and low temperature, ageing can be ignored during the drying process. Then all testing coupons were isothermally aged at prescribed temperatures for $1,2,4,8$, and 16 days. At specified time intervals, specimens were removed from the oven and cooled down to ambient temperature.

\subsection{Characterization}

\subsubsection{Microscopy observation}

Optical microscopy was used to observe the morphology of epoxy cube aged at different ageing conditions. A thin layer of the specimen, as shown in Fig.2, was taken out for micro examination. The color change observed in the micrographs illustrated the formation of the oxidized surface layer. The damage generated on the free surfaces of the composites was observed with scanning electron microscopy (SEM). At a microscopic scale, matrix shrinkage and fiber-matrix debonding were observed to 


\section{Results and discussions}

\subsection{Color change}

Fig.4 [34] and Fig.5 show the color change of specimens during the thermal ageing. The epoxy cube turned black when exposure time reached 16 days at $180{ }^{\circ} \mathrm{C}$, while there is no significant change in the specimens aged at $90{ }^{\circ} \mathrm{C}$ and $110{ }^{\circ} \mathrm{C}$ (Fig. 4a). Fig.4b shows that the oxidized layer, which is indicated by the darker region, is distinctly visible near the surfaces exposed to air. The inner core of epoxy cubes might be protected from oxidation and thus appeared a lighter color. Compared with 
the pure polymer, the surface resin of the braided composite gave a brownish tinge to the specimens as ageing time increased (Fig.5b). Color change indicates that there are chemical reactions occurred in the epoxy resin due to thermo-oxidation. The color depth shows that the ageing was intensified with the increase of temperature and exposure time. And the ageing temperature has much more significant effect. The epoxy matrix oxidation would influence the compressive behaviors of the braided composite significantly.

\subsection{Microscopic morphologies}

\subsubsection{Thermo-oxidation of resin}

Post-curing or thermolysis might occur in the whole specimen under high temperatures, while oxidative degradation just occurred within the region close to the exposed surfaces. Fig.6 shows the formation of oxidized layer in the neat resin coupons. The oxidized layer appears darker than the specimen core. Distinct oxidation layer growth can be observed at high temperatures (for example, $130{ }^{\circ} \mathrm{C}$ and $180{ }^{\circ} \mathrm{C}$ ), but at lower temperatures (for example, $90{ }^{\circ} \mathrm{C}$ and $110{ }^{\circ} \mathrm{C}$ ), the oxidation layer is not discernable. High temperature may be a catalyst for resin oxidation. Fig.6b, cited from our previous work [34], shows the epoxy cubes isothermally aged in air at $180{ }^{\circ} \mathrm{C}$ for different time periods. Posterization technology was used to enhance the micrographs. As an example, Fig.6c shows a specimen exposed at $180^{\circ} \mathrm{C}$ for 8 days. Uneven color distributions show three distinct material phases, representing different oxidation states. The transition region (region (2)) between the outside oxidized layer (region (1)) and inner un-oxidized core (region (3)) is the active oxidation zone (where a mixture of oxidized and un-oxidized polymers exist). And the region composed of the oxidized and active oxidation zones is referred to as 'the oxidative surface layer' herein. It is easy to define the oxidative layer and measure the thickness in the enhanced micrographs. The evolution of the oxidative surface layer thickness is illustrated in Fig.6d. The thickness is seen to approach a plateau value of $0.8 \mathrm{~mm}$ as the oxidation growth rate reduces considerably for longer ageing time period. That is to say, the oxidized layer may reach a limit thickness. The generated dense oxidized 
layer will protect the inner epoxy from further oxidation.

\subsubsection{Photomicrographs of composite coupons}

Figs.7(a-b) and both with our previous work Figs.7(c-d) [34] show the progressive morphology changes of 3-D braided composite specimens aged at different temperatures. Extremely different surface morphologies can be observed. At lower temperatures $\left(90{ }^{\circ} \mathrm{C}\right)$, as illustrated in Fig.7a, there's almost no change on the surface of composites. From Fig.7b, matrix shrinkages are found distributed everywhere on the free surfaces of composite coupons exposed at $130{ }^{\circ} \mathrm{C}$. This type of superfacial damage has been also observed on the composite specimens aged at $110{ }^{\circ} \mathrm{C}, 120{ }^{\circ} \mathrm{C}$ and $180{ }^{\circ} \mathrm{C}$. The shrinkage was also observed by other investigators $[18,22,35]$. The most striking feature that can be seen from Fig.7c is the widespread cracks in the surfaces of specimens aged at $180^{\circ} \mathrm{C}$. The observations bring an important conclusion: ageing temperature and exposure time are the key factors which lead to the thermo-oxidative degradation and damage onset. Fig.7d displays a close-up of cracks. Numerous bare fibers, the indication of fiber/matrix interfacial debonding, can be clearly seen. Previous work $[18,36]$ pointed out that the crack damage is superficial and especially within the oxidized region. Matrix shrinkage caused by thermo-oxidation may account for this phenomenon. Since the oxidized matrix sticks strongly to the fiber tow, the resulting shrinkage mismatch induce a tensile stress gradient near the fiber-matrix interface [16]. At the same time, the interface also degrades and weakens during high-temperature ageing [4, 37]. Once the local stress is greater than the interface bonding strength, cracks will initiate. As ageing time continues, the crack will propagate gradually along the fiber-matrix interface.

\subsection{Attenuated total reflectance Fourier Transform infrared spectroscopy (ATR-FTIR) analyses}

Fig.8 shows the infrared (IR) spectra of the center of epoxy cubes. After the exposure at hot air conditions, the absorption bands near $912 \mathrm{~cm}^{-1}$ disappeared in FTIR (Fourier Transform infrared) spectra of all aged samples. The absorption band located at 912 
$\mathrm{cm}^{-1}$ is the characteristic of epoxy group (not reacted). This observation can be attributed to the post-curing of epoxy resin during thermal ageing. It means that the epoxy cubes are fully cured after being exposured at high temperatures. The post-curing process was documented in the recent work of Mlyniec et al [38]. Elevated temperature facilitates the ring opening reactions and accelerates post-curing process. Post-curing results in increase of crosslink density and then affects the mechanical properties of epoxy resin. The epoxy system will reach the maximum crosslinking density during the early stage of accelerated thermal ageing, independently on the level of conversion resulting from regular curing cycle. Other bands keep almost unchanged, indicating that the center of specimens is protected from oxidation. Fig.9 shows the IR spectra of the surface of the epoxy cubes exposed to different temperatures. For ease of comparison, translating the spectral lines in vertical direction to make their baselines overlapped, as shown in Fig.9b. The characteristic absorption bands near $2958 \mathrm{~cm}^{-1}, 2930 \mathrm{~cm}^{-1}$, and $2870 \mathrm{~cm}^{-1}$ decrease in intensity, especially for specimens aged at $130{ }^{\circ} \mathrm{C}$ and $180{ }^{\circ} \mathrm{C}$. These phenomena demonstrate that $\mathrm{C}-\mathrm{H}$ bond in methyl or methylene between two benzene rings is oxidized. Higher temperatures will increase the rate of oxidation. The IR spectra of different positions in the same specimen are also compared. One example (epoxy coupon aged at $110{ }^{\circ} \mathrm{C}$ for 16 days) is given in Fig.10. Compared with the central epoxy cube, the IR spectra of the surface specimen show an increase in the intensity of absorption bands near $1295 \mathrm{~cm}^{-1}$ and $1246 \mathrm{~cm}^{-1}$. The $\mathrm{C}-\mathrm{O}$ bond in oxidation products, such as carboxylic acid and ester may account for the observations. The pristine specimen is also compared in Fig.10, and the spectral line is almost coincided with that of the center of aged epoxy cube. It means that oxidation reaction only occurred within the exposed surface regions. The same phenomenon is observed for specimens aged at other temperatures.

\subsection{Compression behaviors}

The compressive stress-strain curves of aged specimens were obtained from compression test. As an example, the compression behaviors of the composite 
coupons aged at $90{ }^{\circ} \mathrm{C}$ are given in Fig. 11.

\subsubsection{Effect of ageing temperatures}

Fig.12 and Fig.13 show the change of compression properties of pure resin and the braided composites after ageing in different conditions. Extremely different change trends are observed at different ageing temperatures. For both pure resin and the braided composites aged at $90{ }^{\circ} \mathrm{C}$, there is an obvious enhanced trend with the increase of exposure time. This is probably attributed to the post-curing of epoxy resin, which has been confirmed in section 3.3. Physical ageing (the decreasing of free volume of the resin) may also account for the change [39]. The specimens aged at $110{ }^{\circ} \mathrm{C}$ exhibit an initial increase in modulus and then decline marginally after 1-day ageing. For specimens aged at $120^{\circ} \mathrm{C}, 130{ }^{\circ} \mathrm{C}$ and $180^{\circ} \mathrm{C}$, the compression behaviors decrease with increasing exposure time. There is an obvious increase of initial slope with the increase of temperature, which indicates that high temperature is an accelerating factor in degradation. The property changes may be a consequence of competing effects of thermo-oxidative degradation and matrix stiffening caused by post-curing. The ageing temperature is a determining factor. When ageing at lower temperatures, such as $90{ }^{\circ} \mathrm{C}$, less degradation occurs and strengthening effect will be dominant. While ageing at high temperatures, the post-curing stiffening is overshadowed by serious degradation.

\subsubsection{Ageing mechanisms}

For pure epoxy cubes, as shown in Fig.12, the compressive behaviors change dramatically after 1-day exposure. Then the change slows down and becomes stable at the later stage of ageing. This is because the generated oxidized layer effectively reduces oxygen diffusion and leads to a slower ageing rate at later period. Ultimately, the oxidation is limited within a surface region and the outside oxidation layer will protect the inner cores from further degradation. The optical micrographs (Fig.6) in our work have confirmed this conclusion.

For the braided composites, as shown in Fig.13, the compression behaviors show similar changes with pure resin after ageing at $90{ }^{\circ} \mathrm{C}, 110{ }^{\circ} \mathrm{C}, 120{ }^{\circ} \mathrm{C}$, and $130{ }^{\circ} \mathrm{C}$. A relatively stable state can be achieved after about 4 days. Hence it can be concluded 
that for composites exposed at reasonably low temperatures (maybe below $130{ }^{\circ} \mathrm{C}$, the $T_{g}$ of the investigated composite), at least for a short term, matrix ageing is the main ageing mode. After ageing at $180{ }^{\circ} \mathrm{C}$, however, the compressive behaviors of braided composite continuously decrease with the increase of aging time. Cracks observed in Fig.7c may account for this change. These cracks not only reduce strength, but also create enhanced pathways for oxygen penetration and thus lead to further degradation. The combination of resin degradation and fiber/matrix interface cracking results in the continuous reduction of the compressive behaviors of the braided composite. Besides, it can be seen from Fig.13 that there is a more significant change of compressive modulus than compressive yield strength after ageing.

\section{Conclusions}

The thermal ageing of pure resin and 3-D carbon fiber/epoxy braided composites were investigated experimentally. Five ageing temperature points were selected according to the glass transition temperatures of pure resin (about $110{ }^{\circ} \mathrm{C}$ ) and composite (about $\left.130{ }^{\circ} \mathrm{C}\right)$. The specimens have been exposed to air for $1,2,4,8$, and 16 days at $90{ }^{\circ} \mathrm{C}$, $110{ }^{\circ} \mathrm{C}, 120{ }^{\circ} \mathrm{C}, 130{ }^{\circ} \mathrm{C}$ and $180{ }^{\circ} \mathrm{C}$, respectively. The micro-observation technologies and ATR-FTIR spectroscopy were conducted to illustrate the microstructure changes of specimens exposed to the hot air. Quasi-static compression tests were performed to investigate the thermal ageing effects on mechanical properties of pure resin and the braided composite.

Experimental results revealed that the oxidation degradation only occurred within a surface layer for pure epoxy resin. The oxidized surface layer effectively reduced oxygen diffusion and finally reached a limited thickness to protect the inner cores from further oxidation. High temperatures could catalyze the formation of oxidized layer. Besides, it was also found that:

1. Post-curing would partly enhance the mechanical properties of materials. For epoxy cubes exposed to hot air, the change of compressive behaviors is probably a consequence of competing effects of resin degradation and resin stiffening caused by post-curing. The ageing temperature was a determining factor. 
2. After ageing at temperatures below $130{ }^{\circ} \mathrm{C}$ (the $\mathrm{Tg}$ of braided composite), the compression behaviors of braided composites had similar changing trends with pure resin. It can be concluded that for composites aged at reasonably low temperatures, matrix ageing is the main ageing mode.

3. For composite coupons aged at $180{ }^{\circ} \mathrm{C}$, pronounced fiber/matrix interfacial cracking was observed. The cracks would provide pathways for oxygen diffusion and thus led to further degradation. The resin degradation and interface cracking resulted in the continuous reduction of compressive behaviors of the braided composite. Hence in applications of carbon fiber/epoxy braided composites, extremely high temperatures should be avoided and the interface strengthening is desirable.

\section{Acknowledgements}

The authors acknowledge the financial supports from the Chang Jiang Scholars Program and National Science Foundation of China (Grant Number 11272087 and 11572085). The financial supports from Foundation for the Fok Ying-Tong Education Foundation (Grant No. 141070), Shu-Guang project (Grant No. 14SG31) supported by Shanghai Municipal Education Commission and Shanghai Education Development Foundation, the Fundamental Research Funds for the Central Universities of China and DHU Distinguished Young Professor Program are also gratefully acknowledged. 


\section{Reference}

[1] Mouritz AP, Bannister MK, Falzon PJ, Leong KH. Review of applications for advanced three-dimensional fibre textile composites. Composites Part A - Applied Science and Manufacturing. 1999; 30(12): 1445-61.

[2] Tsotsis TK. Thermo-oxidative aging of composite materials. Journal of Composite Materials. 1995; 29(3): 410-22.

[3] Tsotsis TK. Long-term thermo-oxidative aging in composite materials: Experimental methods. Journal of Composite Materials. 1998; 32(11): 1115-35.

[4] Tsotsis TK, Lee SM. Long-term thermo-oxidative aging in composite materials: Failure mechanisms. Composites Science and Technology. 1998; 58(3-4): 355-68.

[5] Tsotsis TK, Keller S, Lee K, Bardis J, Bish J. Aging of polymeric composite specimens for 5000 hours at elevated pressure and temperature. Composites Science and Technology. 2001; 61(1): 75-86.

[6] Song LL, Li JL. Effects of heat accelerated aging on tensile strength of three dimensional braided/epoxy resin composites. Polymer Composites. 2012; 33(9): 1635-43.

[7] Minervino M, Gigliotti M, Lafarie-Frenot MC, Grandidier JC. The effect of thermo-oxidation on the mechanical behaviour of polymer epoxy materials. Polymer Testing. 2013; 32(6): 1020-8.

[8] Shivakumar KN, Chen H, Holloway G. Effect of thermal fatigue on tensile and flexural properties of carbon/cyanate ester pultruded composite. Journal of Reinforced Plastics and Composites. 2009;28(6):675-89.

[9] Leveque D, Schieffer A, Mavel A, Maire JF. Analysis of how thermal aging affects the long-term mechanical behavior and strength of polymer-matrix composites. Composites Science and Technology. 2005;65(3-4):395-401.

[10] Fan W, Li JL, Wang H, Guo DD. Influence of thermo-oxidative aging on the impact property of conventional and graphene-based carbon fabric composites. Journal of Reinforced Plastics and Composites. 2015;34(2):116-30.

[11] Hague MH, Upadhyaya P, Roy S, Ware T, Voit W, Lu H. The changes in flexural properties and microstructures of carbon fiber bismaleimide composite after exposure to a high temperature. Composite Structures. 2014;108:57-64.

[12] Fan W, Li JL, Guo DD. Effect of thermo-oxidative aging on three-dimensional and four-directional braided carbon fiber/epoxy composite. Journal of Composite Materials. 2015;49(25):3189-202.

[13] Odegard GM, Bandyopadhyay A. Physical aging of epoxy polymers and their composites. Journal of Polymer Science Part B-Polymer Physics. 2011;49(24):1695-716.

[14] Fan W, Li J-1, Zheng Y-y, Liu T-j, Tian X, Sun R-j. Influence of thermo-oxidative aging on the thermal conductivity of carbon fiber fabric reinforced epoxy composites. Polymer Degradation and Stability. 2016;123:162-9.

[15] Awaja F, Arhatari B, Wiesauer K, Leiss E, Stifter D. An investigation of the accelerated thermal degradation of different epoxy resin composites using $\mathrm{x}$-ray microcomputed tomography and optical coherence tomography. Polymer Degradation and Stability. 2009;94(10):1814-24. [16] Colin X, Mavel A, Marais C, Verdu J. Interaction between cracking and oxidation in organic matrix composites. Journal of Composite Materials. 2005;39(15):1371-89.

[17] Zhang C, Binienda WK, Morscher GN, Martin RE, Kohlman LW. Experimental and fem study of thermal cycling induced microcracking in carbon/epoxy triaxial braided composites. 
Composites Part a-Applied Science and Manufacturing. 2013;46:34-44.

[18] Lafarie-Frenot MC, Rouquie S, Ho NQ, Bellenger V. Comparison of damage development in c/epoxy laminates during isothermal ageing or thermal cycling. Composites Part A-Applied Science and Manufacturing. 2006;37(4):662-71.

[19] Marouani S, Curtil L, Hamelin P. Ageing of carbon/epoxy and carbon/vinylester composites used in the reinforcement and/or the repair of civil engineering structures. Composites Part B-Engineering. 2012;43(4):2020-30.

[20] Gigliotti M, Pannier Y, Minervino M, Lafarie-Frenot MC, Corigliano P. The effect of a thermo-oxidative environment on the behaviour of multistable $0 / 90$ unsymmetric composite plates. Composite Structures. 2013;106:863-72.

[21] Ciutacu S, Budrugeac P, Niculae I. Accelerated thermal aging of glass-reinforced epoxy resin under oxygen pressure. Polymer Degradation and Stability. 1991;31(3):365-72.

[22] Dinh Quy V, Gigliotti M, Lafarie-Frenot MC. Experimental characterization of thermo-oxidation-induced shrinkage and damage in polymer-matrix composites. Composites Part A-Applied Science and Manufacturing. 2012;43(4):577-86.

[23] Buch X, Shanahan MER. Thermal and thermo-oxidative ageing of an epoxy adhesive. Polymer Degradation and Stability. 2000;68(3):403-11.

[24] Bowles KJ, Jayne D, Leonhardt TA. Isothermal aging effects on pmr-15 resin. Sampe Quarterly-Society for the Advancement of Material and Process Engineering. 1993;24(2):2-9.

[25] Barjasteh E, Bosze EJ, Tsai YI, Nutt SR. Thermal aging of fiberglass/carbon-fiber hybrid composites. Composites Part a-Applied Science and Manufacturing. 2009;40(12):2038-45. [26] Pei Y-m, Wang K, Zhan M-s, Xu W, Ding X-j. Thermal-oxidative aging of dgeba/epn/lmpa epoxy system: Chemical structure and thermal-mechanical properties. Polymer Degradation and Stability. 2011;96(7):1179-86.

[27] Olivier L, Ho NQ, Grandidier JC, Lafarie-Frenot MC. Characterization by ultra-micro indentation of an oxidized epoxy polymer: Correlation with the predictions of a kinetic model of oxidation. Polymer Degradation and Stability. 2008;93(2):489-97.

[28] Colin X, Marais C, Verdu J. A new method for predicting the thermal oxidation of thermoset matrices - application to an amine crosslinked epoxy. Polymer Testing. 2001;20(7):795-803. [29] Pochiraju KV, Tandon GP, Schoeppner GA. Evolution of stress and deformations in high-temperature polymer matrix composites during thermo-oxidative aging. Mechanics of Time-Dependent Materials. 2008;12(1):45-68.

[30] Tandon GP, Ragland WR. Influence of laminate lay-up on oxidation and damage growth: Isothermal aging. Composites Part A-Applied Science and Manufacturing. 2011;42(9):1127-37. [31] Nam JD, Seferis JC. Anisotropic thermo-oxidative stability of carbon fiber reinforced polymeric composites. Sampe Quarterly-Society for the Advancement of Material and Process Engineering. 1992;24(1):10-8.

[32] Mlyniec A, Korta J, Kudelski R, Uhl T. The influence of the laminate thickness, stacking sequence and thermal aging on the static and dynamic behavior of carbon/epoxy composites. Composite Structures. 2014;118:208-16.

[33] Schoeppner GA, Tandon GP, Ripberger ER. Anisotropic oxidation and weight loss in pmr-15 composites. Composites Part a-Applied Science and Manufacturing. 2007;38(3):890-904.

[34] Zhang M, Zuo C, Sun B, Gu B. Thermal ageing degradation mechanisms on compressive behavior of 3-d braided composites in experimental and numerical study. Composite Structures. 
2016;140:180-91.

[35] Rouquie S, Lafarie-Frenot MC, Cinquin J, Colombaro AM. Thermal cycling of carbon/epoxy laminates in neutral and oxidative environments. Composites Science and Technology.

2005;65(3-4):403-9.

[36] Meador MAB, Lowell CE, Cavano PJ, HerreraFierro P. On the oxidative degradation of nadic endcapped polyimides .1. Effect of thermocycling on weight loss and crack formation. High Performance Polymers. 1996;8(3):363-79.

[37] Jangchud I, Eby RK, Serrano AM, Meador MA. Studies of PAN-based carbon fiber surfaces: Their influence on interfacial bonding with pmr-15 polyimide and composite thermo-oxidative stability. Journal of Advanced Materials. 1996;28(1):19-25.

[38] Mlyniec A, Korta J, Uhl T. Structurally based constitutive model of epoxy adhesives incorporating the influence of post-curing and thermolysis. Composites Part B-Engineering. 2016;86:160-7.

[39] Mendels DA, Leterrier Y, Manson JAE, Nairn JA. The influence of internal stresses on the microbond test ii: Physical aging and adhesion. Journal of Composite Materials.

2002;36(14):1655-76. 


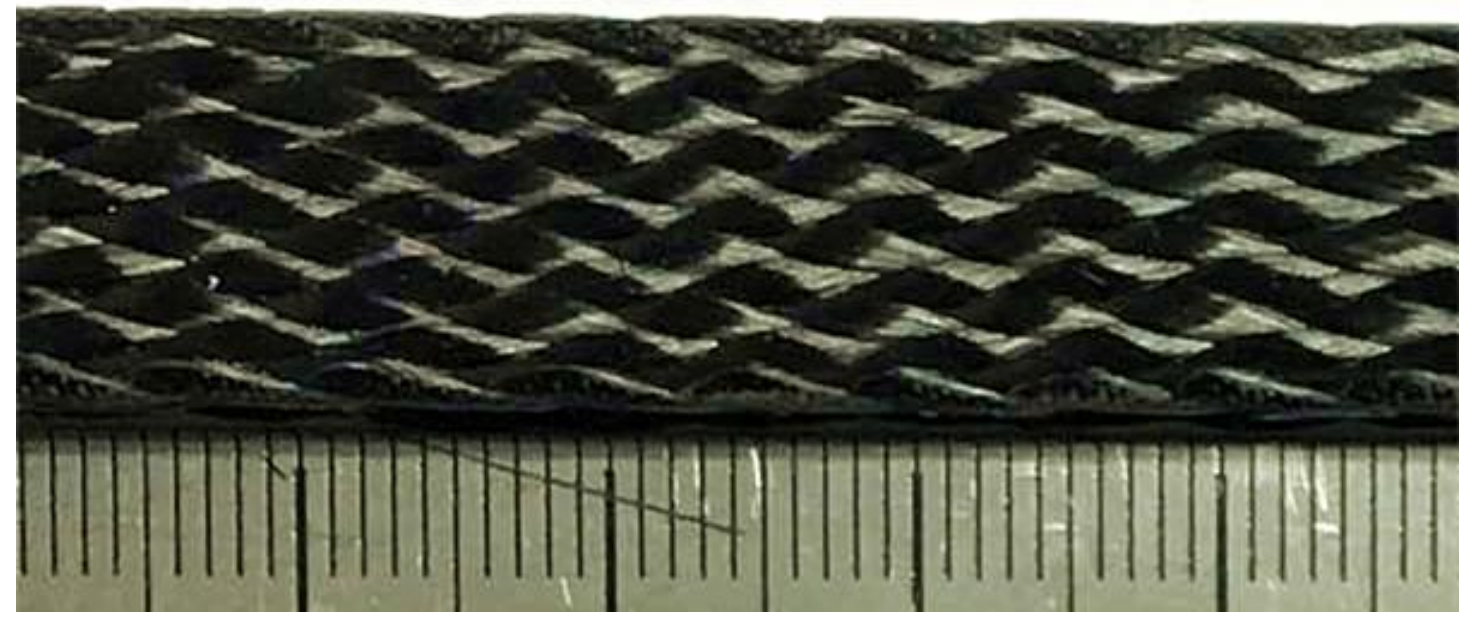

Fig. 13 -D carbon fiber rectangular braided preform in $11 \times 11$ arrays.

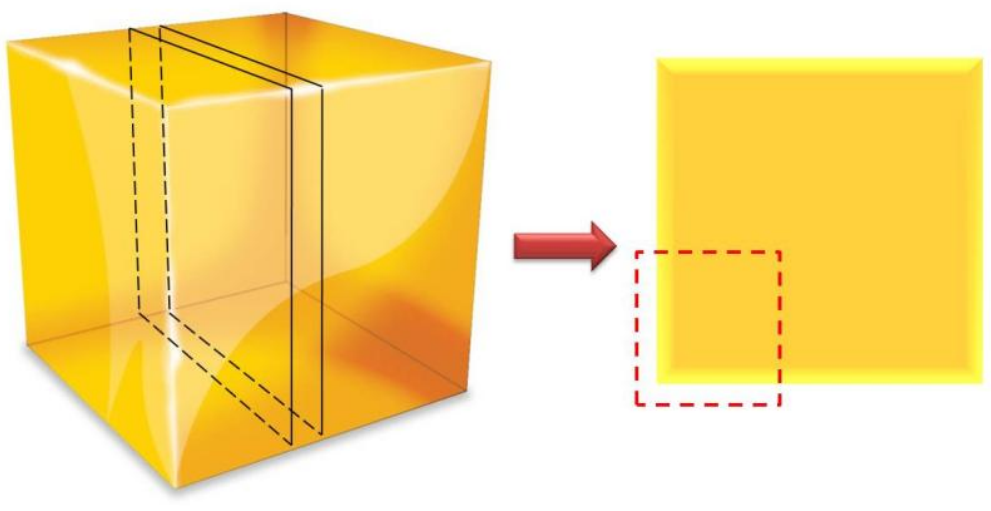

Fig.2 The specimen used for optical microscopy observation. The section in the red dashed box will be observed. 

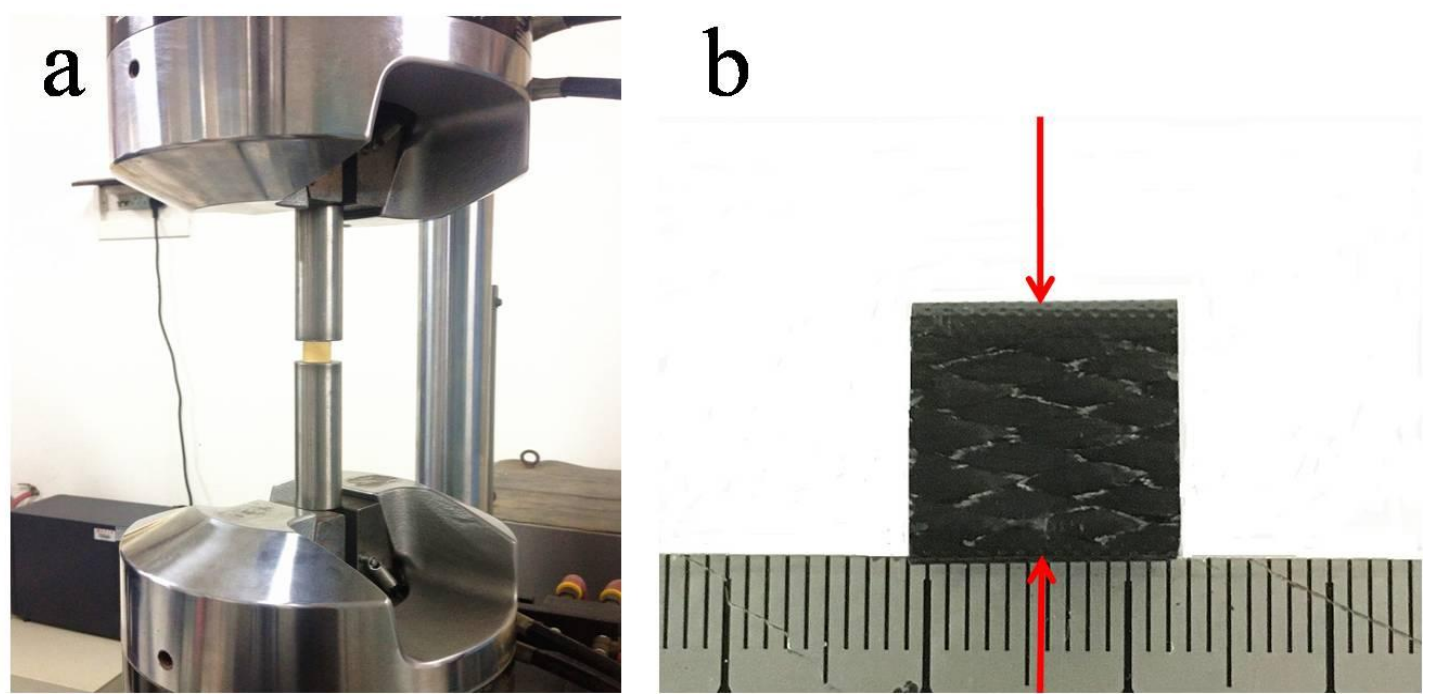

Fig.3 Compression tests

(a) compression test on MTS 810 material test systems; (b) out-of-plane compression.

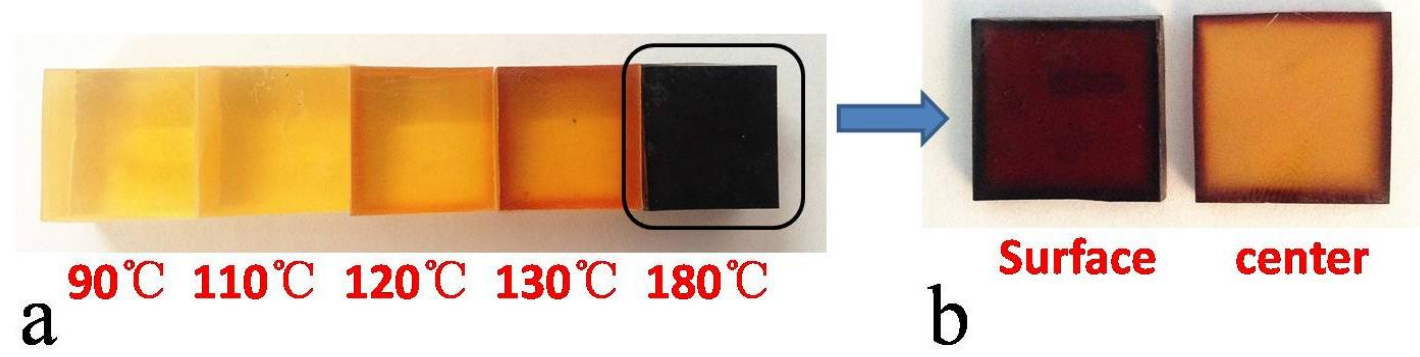

Fig.4 Color change of the epoxy resin cube (a) Epoxy cubes aged at different temperatures for 16days; (b) the surface and the center of epoxy cube aged at $180^{\circ} \mathrm{C}$ 


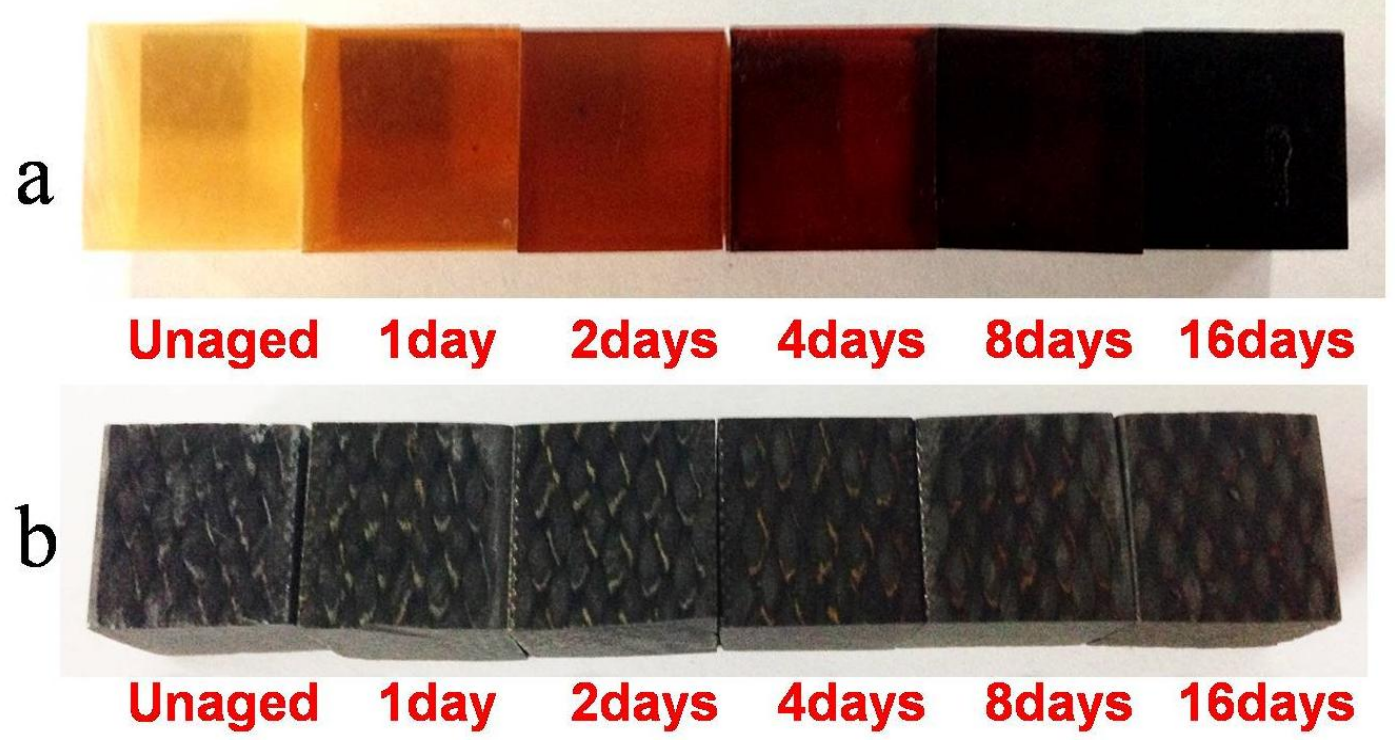

Fig.5 Specimens after thermal ageing at $180^{\circ} \mathrm{C}$ (a) epoxy cubes aged for different time periods; (b) composite coupons aged for different time periods [34]. 


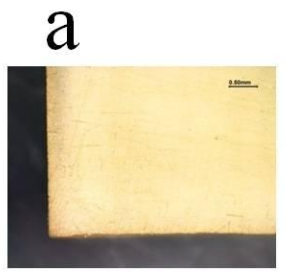

b $90^{\circ} \mathrm{C}$

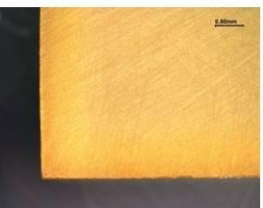

1day

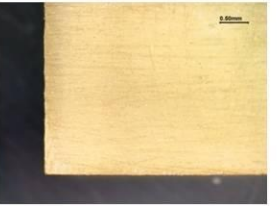

$110^{\circ} \mathrm{C}$

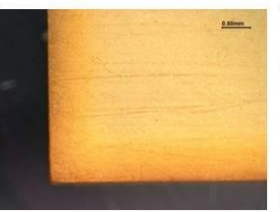

2days

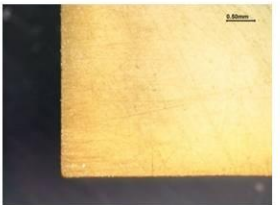

$120^{\circ} \mathrm{C}$

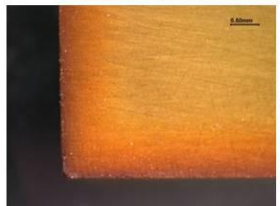

4days

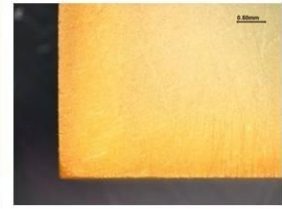

$130^{\circ} \mathrm{C}$

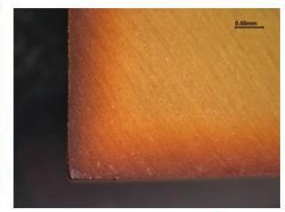

8days

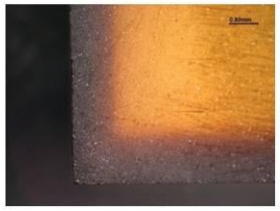

$180^{\circ} \mathrm{C}$

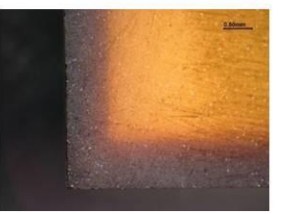

16days

$1.0 \mathrm{~mm}$

$\mathrm{C}$

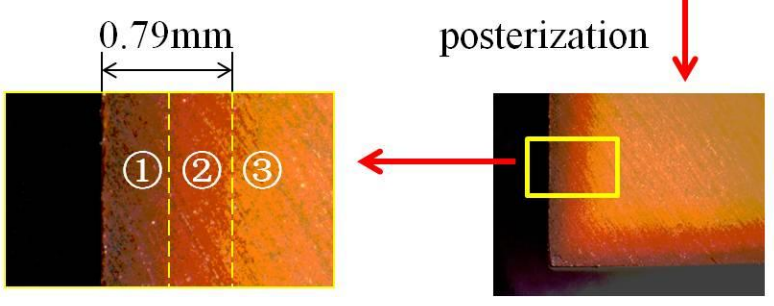

d

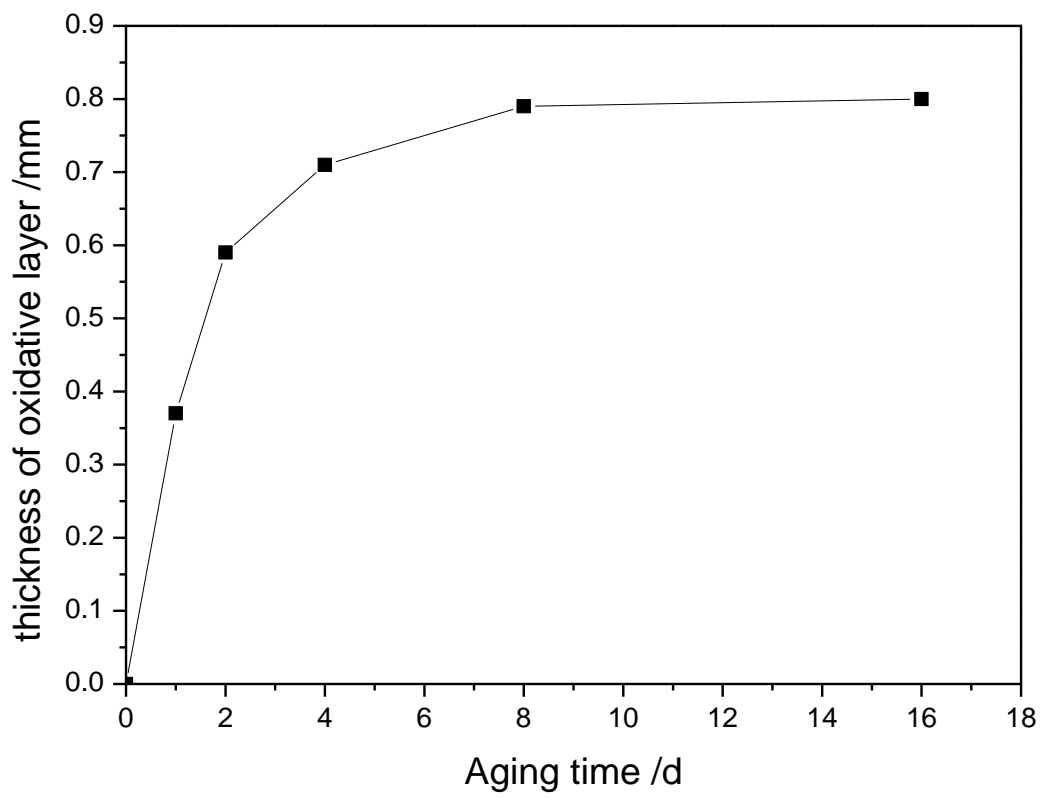

Fig.6 Optical microscopy photographs of epoxy resin showing the formation of oxidized region (a) epoxy cubes aged at different temperatures for 16 days; (b) epoxy cubes exposed at $180^{\circ} \mathrm{C}$ for different time periods [34]; (c) enhanced micrograph of epoxy resin showing 'the oxidative region'; (d) evolution of the oxidative layer thickness in pure resin at $180^{\circ} \mathrm{C}$. 

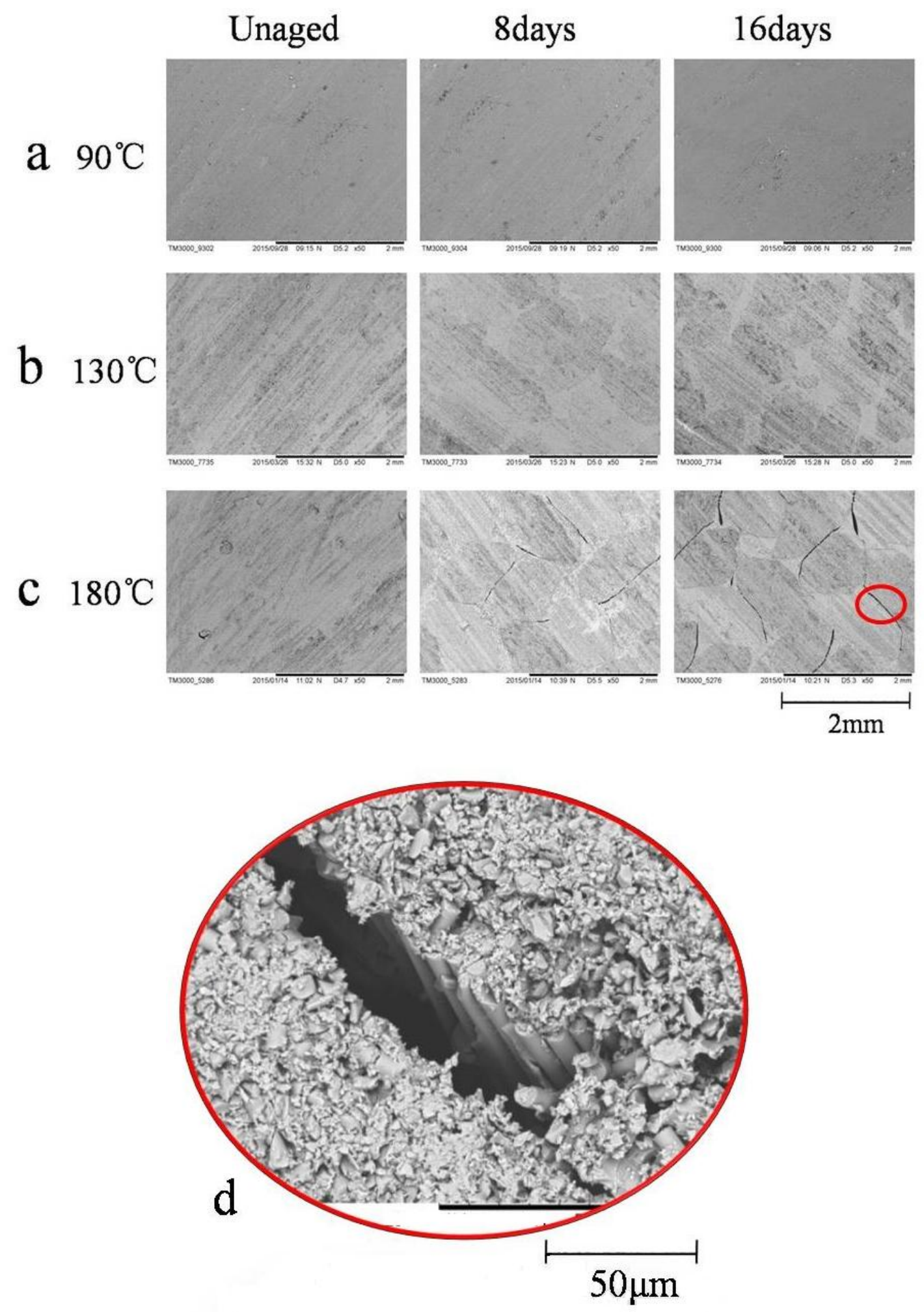

Fig.7 SEM observations of 3-D composite coupons (a) specimens aged at $90^{\circ} \mathrm{C}$; (b) specimens aged at $130^{\circ} \mathrm{C}$; (c) specimens aged at $180^{\circ} \mathrm{C}[34]$;(d) a close-up of cracks observed in (c) [34]. 

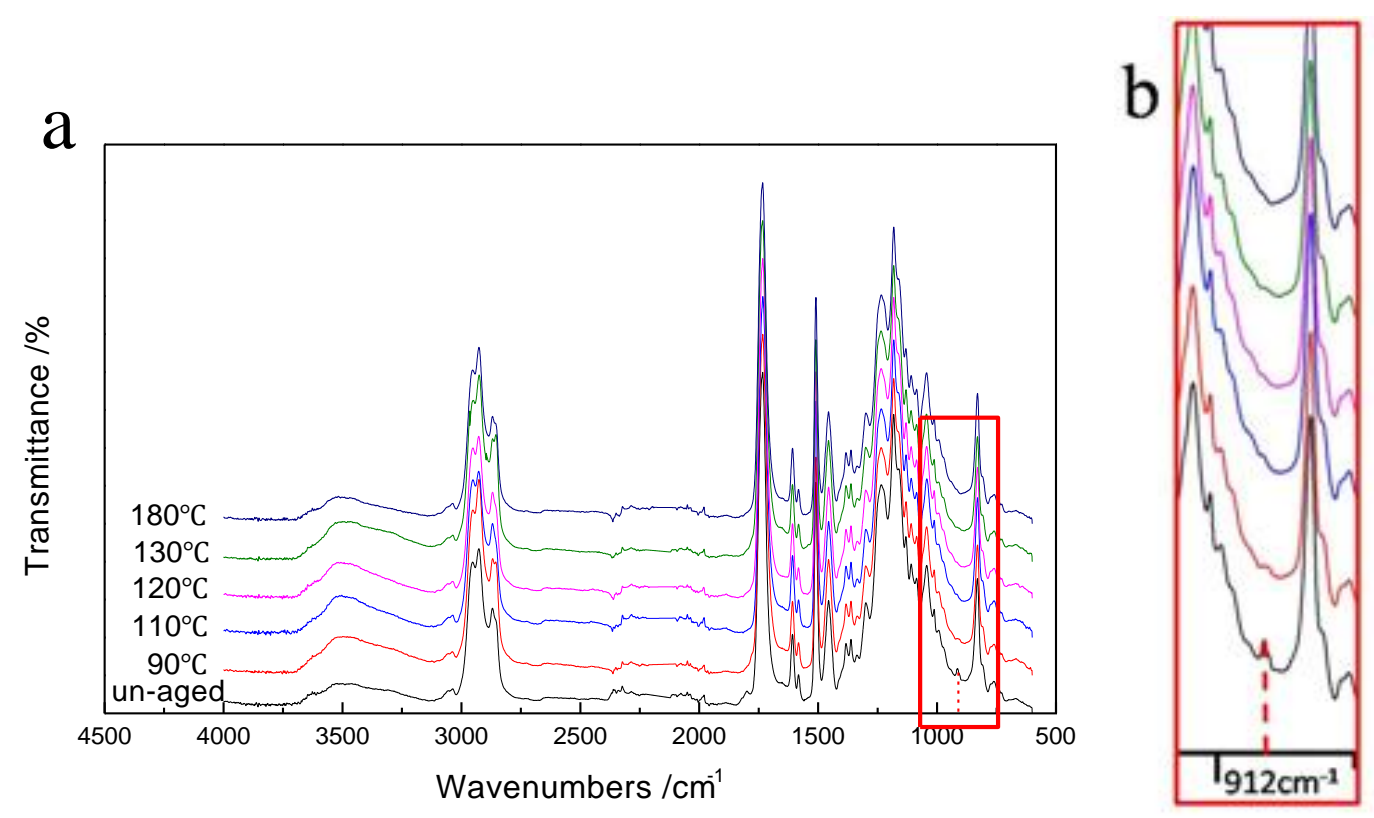

Fig.8 IR spectra of the center of an epoxy cube before ageing and after ageing at different temperatures for 16 days. 
1

2
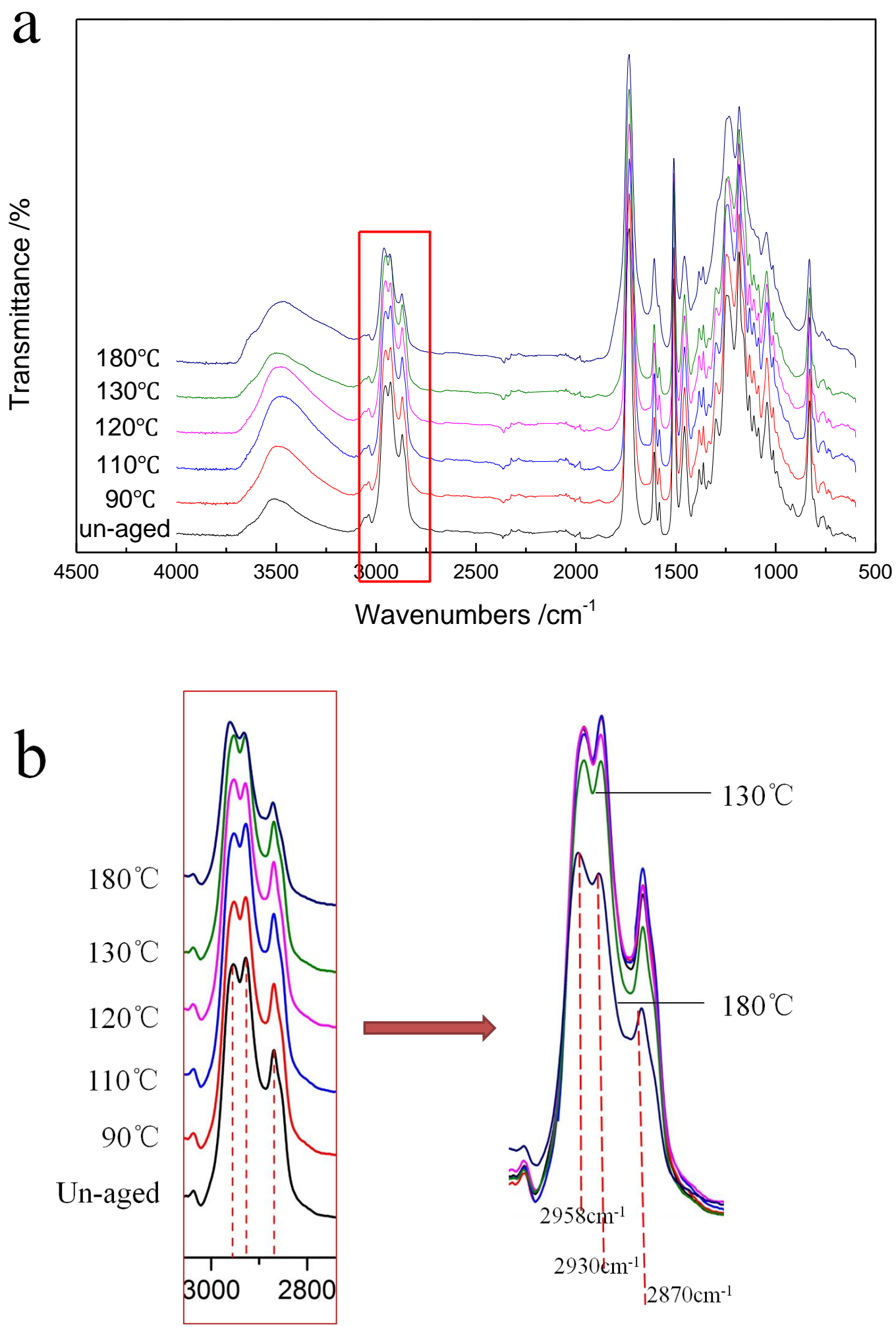

Fig.9 IR spectra of the surface of an epoxy cube before ageing and after ageing at different temperatures for 16 days. 


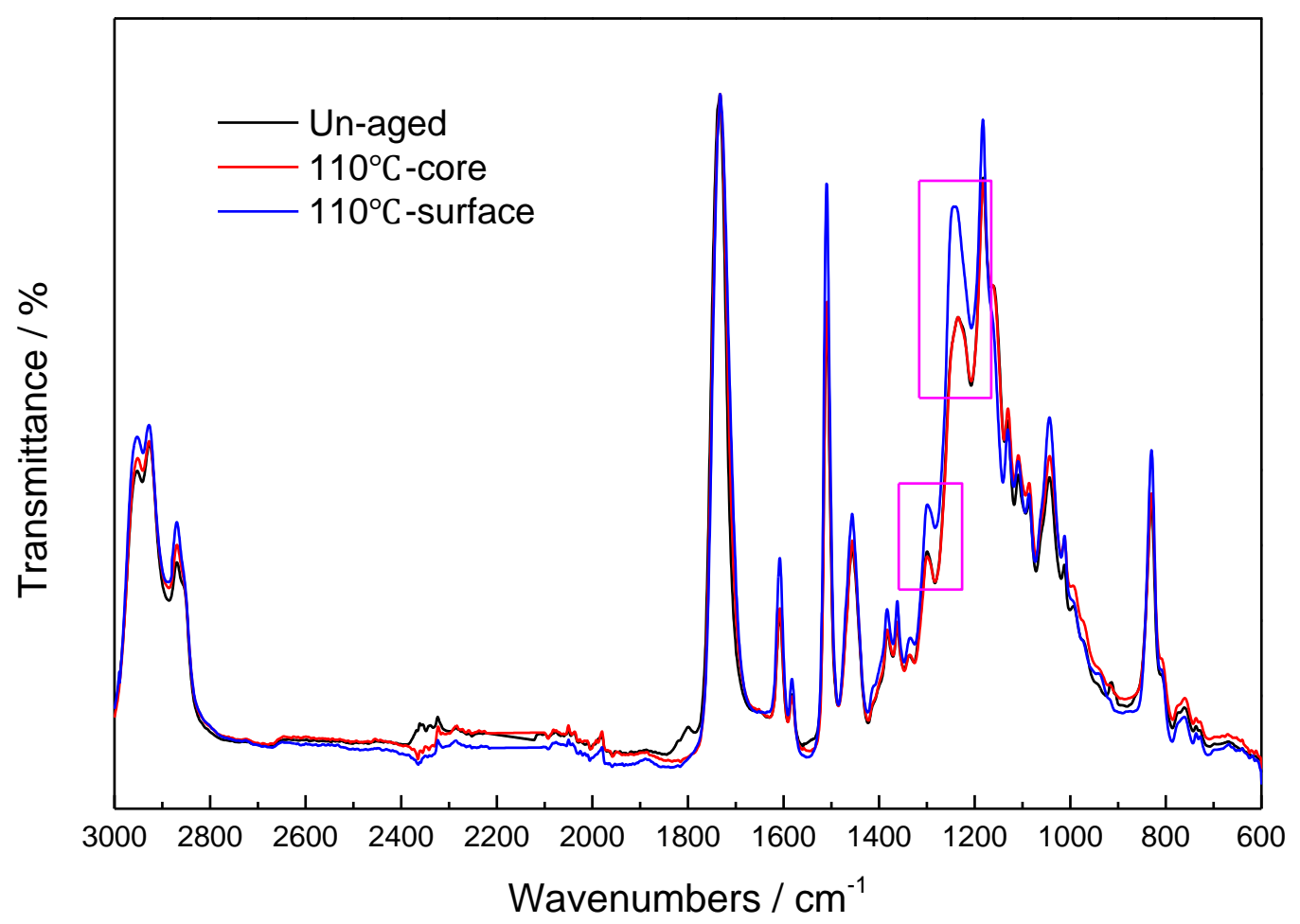

Fig.10 IR spectra of the un-aged resin and the surface and the center of an epoxy cube after ageing at $110^{\circ} \mathrm{C}$ for 16 days. 

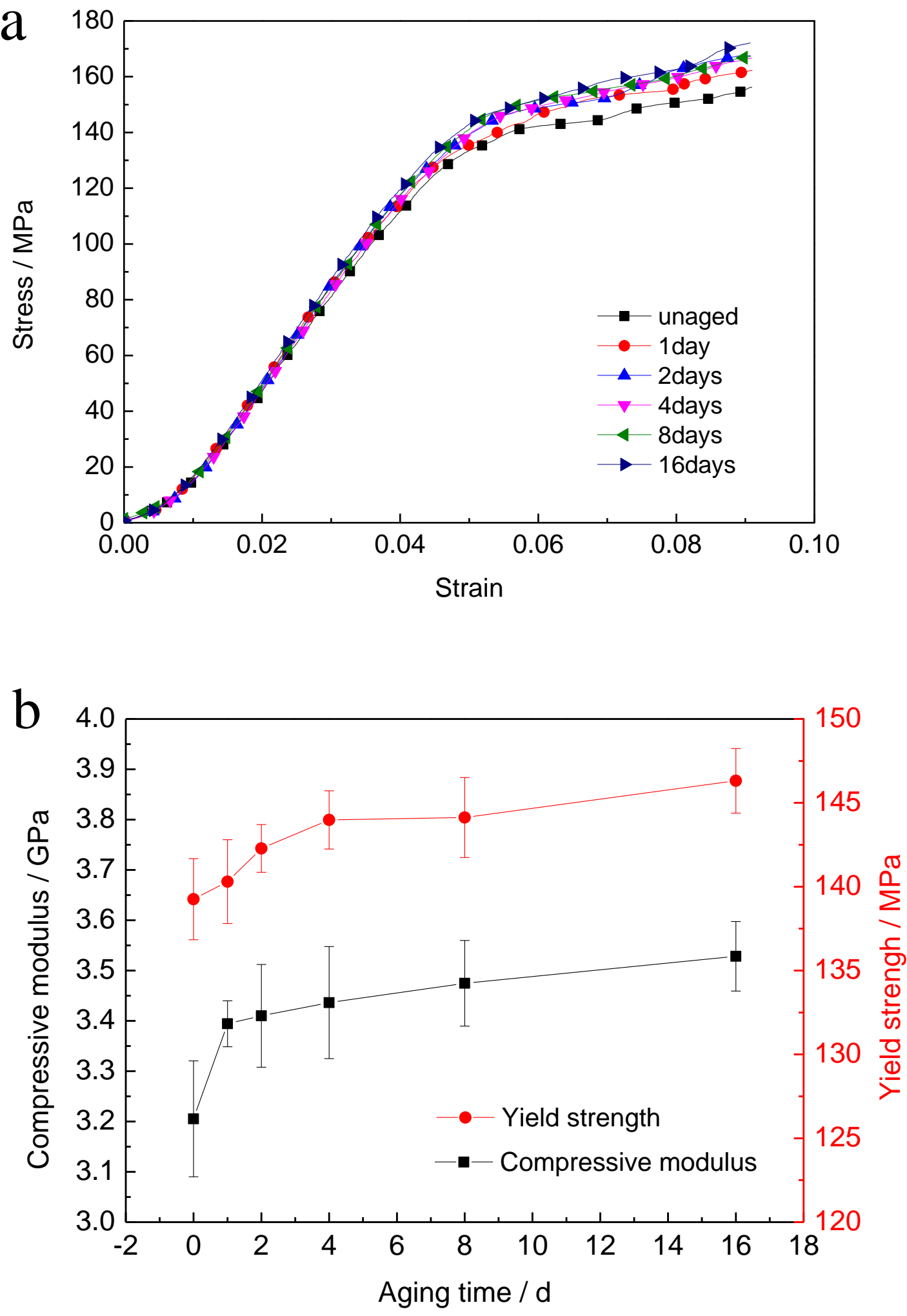

Fig.11 Compression behaviors of 3-D braided composites aged at $90{ }^{\circ} \mathrm{C}$ (a) the compressive stress-strain curves of composite coupons aged at $90{ }^{\circ} \mathrm{C}$ for different time periods; (b) compressive modulus variation and yield strength variation versus aging time. 

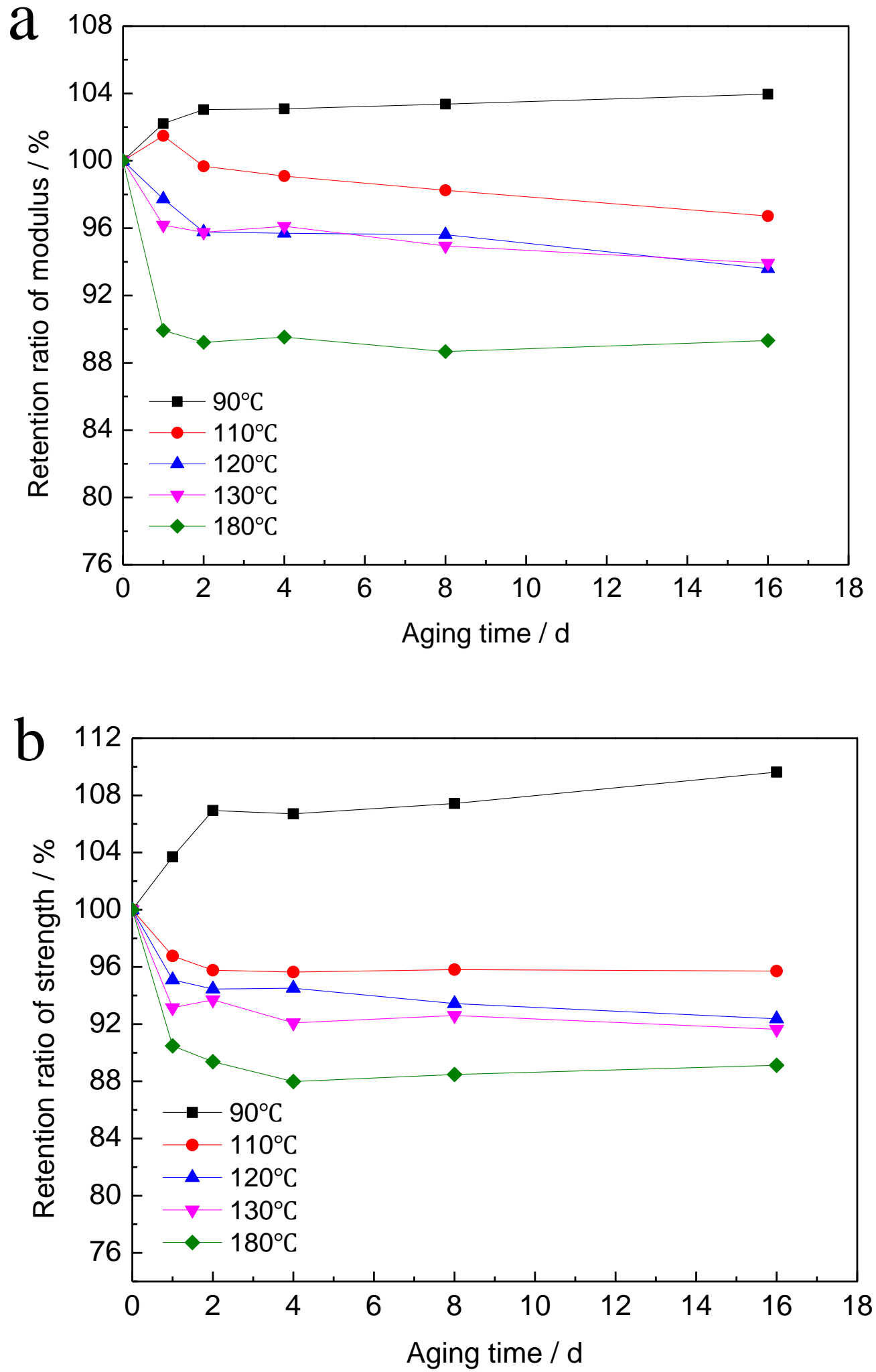

Fig.12 Accelerated thermal ageing effect on compression behaviors of pure resin (a) normalized modulus variation in different ageing conditions; (b) normalized strength variation in different ageing conditions. 

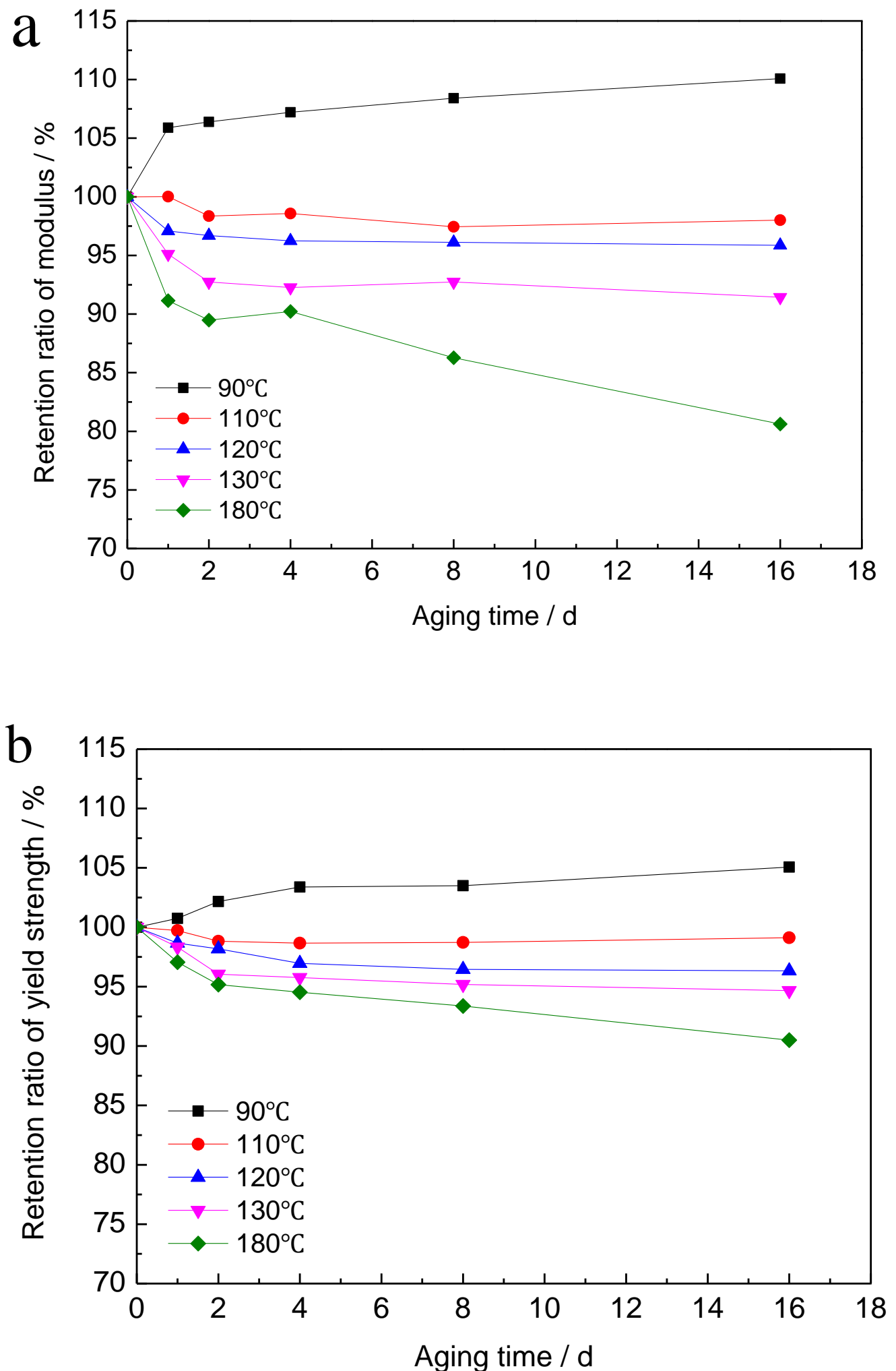

Fig.13 Accelerated thermal ageing effect on compression behaviors of 3-D braided composites (a) normalized modulus variation in different ageing conditions; (b) normalized yield strength variation in different ageing conditions. 